\title{
Working Conditions and Occupational Health: Analyzing the Stressing Factors in Outsourced Employees
}

\author{
Cledinaldo Aparecido Dias*, Isabella Cardoso dos Santos, Marcus Vinicius S. Siqueira \\ University of Brasília - Brazil
}

\begin{abstract}
Considering the different relationships and working conditions of outsourced employees, this study aims to identify the most present stressors among outsourced service providers from a Federal Institution of Higher Education in Brazil. To reach this objective, a descriptive exploratory study with a quantitative approach was carried out. The survey was conducted in the city of Montes Claros/Minas Gerais (Brazil) and involved eighty workers from companies hired by the institution, including armed security guards, porters, cleaners, drivers, gardeners, and administrative assistants. The choice of professionals obeyed non-probabilistic criteria for convenience or accessibility. Data collection was performed by means of a structured questionnaire composed of sixty questions, in a Likert-type frequency interval scale format, in order to identify potential organizational stressors. Results obtained evidenced an expressive set of factors that exert an influence on the presentation of the stress situation by outsourced workers. Amongst the factors associated with stress, the ones that stood out most were those related to organizational communication failures, incentive to competition, lack of expectations of professional growth, insecurity and job instability, since the losing the job is triggered with each new bidding process. The conclusions obtained evidenced the need for greater concern and organizational responsibility with the well-being and health of the outsourced worker and the recognition of their physical and psychological limitations, a care that should go beyond functional aptitude for work.
\end{abstract}

Keywords: Management, mental health, Organizational Studies, people management, Stressors. 